\title{
Perbedaan Sensitivitas Kuman Pseudomonas Aeruginosa Penyebab Infeksi Nosokomial Terhadap Beberapa Antibiotika Generik dan Paten
}

\author{
Ayu Andrian Putri ${ }^{1}$, Roslaili Rasyid ${ }^{2}$, Rahmatini ${ }^{3}$
}

\begin{abstract}
Abstrak
Infeksi nosokomial adalah infeksi yang didapat di rumah sakit, terjadi sesudah 72 jam perawatan pada pasien rawat inap dan bisa juga pada pasien yang dirawat lebih lama dari masa inkubasi suatu penyakit. Menurut penelitian, salah satu kuman penyebab infeksi nosokomial adalah Pseudomonas aeruginosa. Tingginya biaya kesehatan yang bersumber dari obat sebenarnya bisa ditekan secara signifikan jika pasien menggunakan obat generik. Namun telah terjadi salah persepsi di kalangan masyarakat luas bahwa obat generik adalah obat kelas dua yang khasiatnya kurang dibandingkan dengan obat paten. Beberapa penelitian juga sudah membuktikan bahwa efektivitas dari obat generik dan paten adalah sama. Tujuan penelitian ini untuk melihat dan membandingkan zona bebas kuman Pseudomonas aeruginosa penyebab infeksi nosokomial setelah pemberian antibiotika generik dan paten.Penelitian telah dilaksanakan pada bulan Juni 2013 - Desember 2013 di Laboratorium Mikrobiologi Universitas Andalas. Penelitian menggunakan 24 sampel biakan kuman P. aeruginosa dari pasien infeksi nosokomial di RSUP dr. M. Djamil Padang yang ditentukan berdasarkan rumus simple random sampling menggunakan metode difusi cakram Kirby-Bauer dan dihitung zona bebas kuman terhadap 4 antibiotika generik dan paten yang diuji.Dari hasil penelitian ditemukan amoxicillin dan eritromisin generik dan paten tidak menghasilkan zona bebas kuman, zona bebas kuman dari 3 sampel yang diuji dengan kloramfenikol generik lebih besar daripada yang paten sedangkan 21 sampel sisanya sebaliknya, dan zona bebas kuman dari 8 sampel yang diuji dengan siprofloksasin generik lebih besar daripada yang paten sedangkan 16 sampel sisanya sebaliknya.Setelah dilakukan analisis statistik menggunakan SPSS dengan uji Ttest independen menunjukkan bahwa tidak terdapat perbedaan yang bermakna antara sensitivitas kuman Pseudomonas aeruginosa penyebab infeksi nosokomial terhadap kloramfenikol dan siprofloksasin generik dan paten. Sedangkan resistensi yang terjadi pada amoxicillin dan eritromisin diduga dipengaruhi oleh pemberian antibiotik.
\end{abstract}

Kata kunci: Pseudomonas aeruginosa, infeksi nosokomial, sensitivitas, antibiotika generik dan paten

\begin{abstract}
Nosocomial infections are infections acquired in hospitals, occurred after 72 hours of treatment in hospitalized patients and could also in patients treated for longer than the incubation period of a disease. According to research, one of the causative organism of nosocomial infection is Pseudomonas aeruginosa. The high cost of health care is actually derived from the drug can be suppressed significantly if patients use generics. But, there has been a wrong perception among the public that generic drugs are the properties of two classes of drugs less than branded name medicine. Some of studies proved that the effectiveness of generic drugs and patent are the same. The goal was to see and compare the germ-free zone of Pseudomonas aeruginosa causing nosocomial infection after given the antibiotics generic and branded name. The experiment was conducted from June 2013 to December 2013 at the Microbiology Laboratory of the Andalas University. The experiment used 24 sample of $P$. aeruginosa from nosocomial infection patient in RSUP Dr. M. Djamil Padang that determinded by simple random sampling formula and used KirbyBauer diffusion method then counted the free zone germ towards 4 antibiotics generic and branded name. From the results founded that generic and branded name of amoxicillin and erythromycin did not have results of germ-free zone,
\end{abstract}


the germ-free zone of 3 sample that tested with generic kloramfenikol is bigger than the branded name and the less are the other way and the germ-free zone of 8 sample that tested with generic siprofloksasin is bigger than the branded name and the less are the other way.After doing statistical analysis using SPSS through the independent $T$ test showed that there was no significant difference between the sensitivity of Pseudomonas aeruginosa causes of nosocomial infections between generic and branded name of chloramphenicol and ciprofloxacin. Whereas about the resistance in amoxicillin dan eritromisin assumed because the influenced by irrasional antibiotics given in hospital and the prescription from the doctor.

Keywords: Pseudomonas aeruginosa, nosocomial infection, sensitivity, generic and branded name antibiotic

Affiliasi penulis : 1. Pendidikan Dokter Fakultas Kedokteran Universitas Andalas Padang, 2. Bagian Mikrobiologi FK UNAND, 3. Bagian Farmakologi FK UNAND.

Korespondensi : Ayu Andrian Putri, email: ayu.andrian@gmail.com, Telp: 082172616379

\section{PENDAHULUAN}

Pseudomonas aeruginosa adalah kuman patogen oportunistik yang dapat menyebabkan keadaan yang invasif pada pasien dengan penyakit kritis maupun pasien yang memiliki tingkat imunitas yang sangat rendah. Umumnya kuman ini sering ditemukan sebagai penyebab infeksi nosokomial di rumah sakit khususnya di Intensive Care Unit (ICU). ${ }^{1}$

Rumah sakit bisa membahayakan pasiennya melalui infeksi karena mikroorganisme patogen yang ada di rumah sakit tersebut. Istilah untuk infeksi ini adalah infeksi nosokomial, dan sudah dikenal sejak tahun 1960-an. ${ }^{2}$

Bakteri memiliki beberapa mekanisme sehingga bisa dikatakan resisten terhadap antibiotika. Resistensi ini dibagi menjadi dua kelompok, resistensi alami dan resistensi didapat. Resistensi alami yaitu suatu sifat bakteri yang memang kurang atau tidak aktif terhadap suatu antibiotika, seperti $P$. aeruginosa yang tidak pernah sensitif terhadap kloramfenikol. Sedangkan resistensi didapat yaitu resistensi yang terjadi pada bakteri yang sebelumnya sensitif kemudian bisa berubah menjadi resisten. ${ }^{3}$

Tingginya biaya kesehatan yang bersumber dari obat sebenarnya bisa ditekan secara signifikan jika pasien menggunakan obat generik. Namun telah terjadi salah persepsi yang mendalam dan berlangsung lama mengenai manfaat dan kelebihan obat generik. Muncul persepsi di kalangan masyarakat luas bahwa obat generik adalah obat kelas dua yang khasiatnya kalah jauh dibanding obat paten. Sebenarnya kualitas obat generik tidak kalah dengan obat bermerek lainnya. Hal ini dikarenakan obat generik juga mengikuti persyaratan dalam Cara Pembuatan Obat yang Baik (CPOB) yang dikeluarkan oleh Badan Pengawas Obat dan Makanan Republik Indonesia (BPOM RI). Obat generik juga harus lulus uji bioavailabilitas / bioekivalensi (BA/BE). Uji ini dilakukan untuk menjaga mutu obat generik. ${ }^{4}$

\section{METODE}

Penelitian ini merupakan penelitian eksperimental, menggunakan desain Cross Sectional. Penelitian dilaksanakan di Laboratorium Mikrobiologi Fakultas Kedokteran Universitas Andalas periode Juni 2013 - Desember 2013. Sampel penelitian ini adalah koloni/ isolasi kuman $P$. aeruginosa penyebab infeksi nosokomial di laboratorium mikrobiologi RSUP M. Djamil Padang yang diambil berdasarkan sistem simple random sampling. Jumlah sampel dihitung berdasarkan minimal adequate sample size dan didapatkan jumlah sampel 24 spesimen pasien terinfeksi nosokomial. Variabel bebas peneltian ini adalah antibiotika golongan Penisilin (amoxicillin), Makrolid (eritromisin), Kloramfenikol (kloramfenikol) dan Fluorokuinolon (siprofloksasin) generik dan paten. Variabel terikat penelitian ini adalah sensitivitas kuman $P$. aeruginosa. Obat generik adalah nama obat yang sama dengan zat aktif berkhasiat yang dikandungnya, sesuai nama resmi International Non Proprietary Names yang telah di tetapkan dalam Farmakope Indonesia. Obat paten adalah hak paten yang diberikan kepada industri farmasi pada obat baru yang ditemukannya berdasarkan riset. Industri farmasi tersebut diberi hak paten untuk memproduksi dan memasarkannya, setelah melalui berbagai tahapan uji klinis sesuai aturan yang telah ditetapkan secara internasional. Uji sensitivitas adalah penentuan terhadap bakteri penyebab penyakit yang 
kemungkinan menunjukkan resistensi terhadap suatu antimikroba atau kemampuan suatu antimikroba untuk menghambat pertumbuhan bakteri yang tumbuh in vitro, sehingga dapat dipilih sebagai antimikroba yang berpotensi untuk pengobatan.

Hasil pengamatan di Laboratorium yang diperoleh merupakan data kualitatif dan kuantitatif yang disajikan dalam bentuk gambar dan tabel.

\section{HASIL}

Tabel 1. Rata-rata Zona Bebas Kuman Setelah Pemberian Amoxicillin dan Eritromisin Generik dan Paten.

\begin{tabular}{|c|c|c|}
\hline \multirow{2}{*}{ No } & \multicolumn{2}{|c|}{ amoxicillin \& eritromisin (mm) } \\
\hline & Generik & Paten \\
\hline 1. & 0 & 0 \\
\hline 2. & 0 & 0 \\
\hline 3. & 0 & 0 \\
\hline 4. & 0 & 0 \\
\hline 5. & 0 & 0 \\
\hline 6. & 0 & 0 \\
\hline 7. & 0 & 0 \\
\hline 8. & 0 & 0 \\
\hline 9. & 0 & 0 \\
\hline 10. & 0 & 0 \\
\hline 11. & 0 & 0 \\
\hline 12. & 0 & 0 \\
\hline 13. & 0 & 0 \\
\hline 14. & 0 & 0 \\
\hline 15. & 0 & 0 \\
\hline 16. & 0 & 0 \\
\hline 17. & 0 & 0 \\
\hline 18. & 0 & 0 \\
\hline 19. & 0 & 0 \\
\hline 20. & 0 & 0 \\
\hline 21. & 0 & 0 \\
\hline 22. & 0 & 0 \\
\hline 23. & 0 & 0 \\
\hline 24. & 0 & 0 \\
\hline
\end{tabular}

Tabel 1 menunjukkan bahwa amoxicillin dan eritromicin baik generik maupun paten tidak menghasilkan zona bebas kuman

Tabel 2. Rata-rata Zona Bebas Kuman Setelah Pemberian Kloramfenikol Generik dan Paten.

\begin{tabular}{|c|c|c|}
\hline \multirow{2}{*}{ No } & \multicolumn{2}{|c|}{ kloramfenikol (mm) } \\
\hline & Generik & Paten \\
\hline 1. & 0 & 0 \\
\hline 2. & 0 & 0 \\
\hline 3. & 11 & 15 \\
\hline 4. & 0 & 0 \\
\hline 5. & 15 & 18 \\
\hline 6. & 14 & 16.5 \\
\hline 7. & 15 & 15 \\
\hline 8. & 17.5 & 20 \\
\hline 9. & 20 & 20 \\
\hline 10. & 25 & 17.5 \\
\hline 11. & 10 & 17 \\
\hline 12. & 16 & 12.5 \\
\hline 13. & 11 & 13.5 \\
\hline 14. & 0 & 0 \\
\hline 15. & 0 & 0 \\
\hline 16. & 30,5 & 30 \\
\hline 17. & 0 & 0 \\
\hline 18. & 0 & 0 \\
\hline 19. & 0 & 0 \\
\hline 20. & 0 & 0 \\
\hline 21. & 16 & 20 \\
\hline 22. & 21 & 23 \\
\hline 23. & 10 & 15 \\
\hline 24. & 11 & 14 \\
\hline
\end{tabular}

Tabel 2 menunjukkan bahwa ada 3 sampel yang zona bebas kuman dari obat generiknya lebih besar daripada yang paten yaitu sampel nomor 10,12 dan 16, dan 21 sampel sisanya menunjukkan obat paten lebih baik daripada obat generik.

Tabel 3 menunjukkan bahwa ada 8 sampel yang zona bebas kuman dari obat generiknya lebih besar daripada yang paten yaitu sampel nomor $1,3,8,11,12,15,20$ dan 21 , dan 16 sampel sisanya menunjukkan obat paten lebih baik daripada obat generik. 
Tabel 3. Rata-Rata Zona Bebas Kuman Setelah Pemberian Siprofloksasin Generik dan Paten

\begin{tabular}{|c|c|c|}
\hline \multirow{2}{*}{ No } & \multicolumn{2}{|c|}{ siprofloksasin $(\mathrm{mm})$} \\
\hline & Generik & Paten \\
\hline 1. & 36.5 & 32 \\
\hline 2. & 25 & 26 \\
\hline 3. & 34.5 & 30 \\
\hline 4. & 27.5 & 32.5 \\
\hline 5. & 37.5 & 37.5 \\
\hline 6. & 40 & 44.5 \\
\hline 7. & 42.5 & 42.5 \\
\hline 8. & 44.5 & 37.5 \\
\hline 9. & 35 & 40 \\
\hline 10. & 35 & 35 \\
\hline 11. & 40 & 35 \\
\hline 12. & 45 & 40 \\
\hline 13. & 35.5 & 45 \\
\hline 14. & 20 & 38.5 \\
\hline 15. & 23 & 20.5 \\
\hline 16. & 16 & 20 \\
\hline 17. & 12.5 & 12.5 \\
\hline 18. & 10 & 14.5 \\
\hline 19. & 5 & 5 \\
\hline 20. & 11 & 10 \\
\hline 21. & 33.5 & 30.5 \\
\hline 22. & 21 & 23.5 \\
\hline 23. & 33.5 & 39 \\
\hline 24. & 39.5 & 39.5 \\
\hline
\end{tabular}

\section{PEMBAHASAN}

Pada tabel 2 dan 3 dapat dilihat bahwa sebagian besar rata-rata zona bebas kuman Pseudomonas aeruginosa penyebab infeksi nosokomial terhadap siprofloksasin dan kloramfenikol paten lebih besar dari pada yang generik. Hasil analisis statistik menggunakan SPSS melalui uji $\mathrm{T}$ tidak berpasangan dengan derajat kepercayaan 95\% didapatkan signifikansi dari kedua macam antibiotika tersebut $\geq 0,05$, yang berarti tidak terdapat perbedaan yang bermakna antara sensitivitas kuman Pseudomonas aeruginosa penyebab infeksi nosokomial terhadap antibiotika kloramfenikol dan siprofloksasin yang generik dengan antibiotika kloramfenikol dan siprofloksasin yang paten.
Tabel 4. Hasil uji T Tidak Berpasangan

\begin{tabular}{ccc}
\hline No & Antibiotika & Sig ( p ) \\
\hline $\mathbf{1 .}$ & amoxicillin & 0 \\
\hline $\mathbf{2 .}$ & eritromisin & 0 \\
\hline $\mathbf{3 .}$ & kloramfenikol & 0,350 \\
\hline $\mathbf{4 .}$ & siprofloksasin & 0,859 \\
\hline
\end{tabular}

Hal ini dapat terjadi karena zat aktif, bahan tambahan, kekuatan maupun dosis yang dikandung di dalam kedua obat ini sama. Perbedaan yang mencolok dari obat generik dan paten hanya terlihat dari harga, dikarenakan di dalam obat paten terdapat biaya pemasaran, biaya penelitian, laba perusahaan dan biaya pendaftaran nama dagang. ${ }^{5}$ Penggunaan obat generik juga dapat dipengaruhi pemberian resep oleh dokter. Tidak semua dokter dengan senang hati memberikan resep obat generik kepada pasien. Banyak alasan yang menjadi latar belakang hal tersebut, salah satunya adalah pandangan masyarakat yang menganggap remeh obat generik sehingga akhirnya akan mengurangi reputasi dokter. Hal lain yang bisa mempengaruhi yaitu adanya pesan sponsor kepada dokter tersebut dan belum adanya obat generik dari obat paten yang akan diberikan kepada pasien. Selain itu, pasien biasanya juga enggan untuk meminta obat generik kepada dokternya sehingga penggunaan obat generik dengan resep dokter masih sangat kurang. ${ }^{4}$

Keadaan ini sesuai dengan penelitian yang dilakukan oleh Happy pada tahun 2007 yang menunjukkan tidak adanya perbedaan yang signifikan dari ampisillin, eritromisin, amoksisilin dan tetrasiklin generik dan paten terhadap kuman Staphylococcus aureus dan Sejalan juga dengan penelitian yang dilakukan oleh Guptaja Kusumah Nagara pada tahun 2007 yang menunjukkan tidak adanya perbedaan yang signifikan dari antibiotika Cefoperazon - As. Klavulanat generik dan paten dalam berbagai konsentrasi terhadap kuman Pseudomonas aeruginosa. $^{6,7}$

Rata-rata zona bebas yang dihasilkan apabila dikonversikan ke dalam standar yang dikeluarkan oleh 
National Committee for Clinical Laboratory Standards (NCCLS), amoxicilin dan eritromisin termasuk ke dalam kriteria resisten, karena kedua obat ini sama sekali tidak menampakkan hasil diameter zona bebas, dalam kata lain diameternya $\leq 15 \mathrm{~mm}$. Secara garis besar, ada beberapa mekanisme kuman dapat menjadi resisten terhadap suatu antibiotika diantaranya obat tidak dapat mencapai tempat kerjanya didalam sel mikroba, inaktivasi obat dan mikroba mengubah tempat ikatan antibiotika/ modifikasi target antibiotika. ${ }^{8}$ Keadaan Multi Drug Resistance (MDR) pada kuman Pseudomonas aeruginosa penyebab infeksi nosokomial diduga karena penggunaan antibiotika yang tidak rasional di rumah sakit. Berdasarkan penelitian yang dilakukan sistem The National Nosocomial Infection Surveillance (NNIS) dan beberapa penelitian lain yang dilakukan di bangsal Non-Intensive Care Unit (ICU) dan ICU mendapatkan hubungan langsung antara penggunaan antibiotika yang tinggi terhadap insiden terjadinya resistensi obat. Studi ini menemukan adanya pemberian terapi yang tidak seharusnya, dosis yang tidak adekuat serta durasi penggunaan obat yang tidak benar di rumah sakit. Hal ini akan berpengaruh terhadap perubahan pola bakteri penyebab infeksi dan pola resistensinya terhadap berbagai antibiotika. ${ }^{2}$

Terjadinya penggunaan antibiotika yang tidak rasional telah diamati sejak lama. Suatu survei yang dilakukan oleh tim Anti Microbial Resistance in Indonesia (AMRIN) study di RS. Dr. Soetomo Surabaya dan RSUP. Dr. Kariadi Semarang tahun 2002 menunjukkan 83\% pasien mendapat antibiotika dan penggunaan antibiotika yang tidak rasional sebanyak 60\%. Dari 2058 penulisan resep dapat dikategorikan 53\% digunakan sebagai terapi, 15\% sebagai pencegahan dan $32 \%$ penulisan tidak diketahui indikasinya. ${ }^{8}$

\section{KESIMPULAN}

1. Kuman Pseudomonas aeruginosa penyebab infeksi nosokomial yang diuji termasuk ke kriteria resisten terhadap antibiotika amoxicillin, eritromicin dan kloramfenikol generik dan paten, dan kriteria sensitif terhadap antibiotika siprofloksasin generik dan paten.

2. Tidak ada perbedaan yang bermakna dari sensitivitas kuman Pseudomonas aeruginosa penyebab infeksi nosokomial yang diuji terhadap antibiotika kloramfenikol dan siprofloksasin generik dan paten.

\section{DAFTAR PUSTAKA}

1. Slama, Karim B, Skander G, Ahlem J, Meriem M, Chedlia F, et al. Epidemiology of pseudomonas aeruginosa in intensive care unit and otolaryngology department of a tunisian hospital. African Journal of Microbiology Research. 2011;5(19):1.

2. Editorial. Pseudomonas, penyebab infeksi nosokomial. Cermin Dunia Kedokteran. 2011:1.

3. Harniza Y. Pola resistensi bakteri yang diisolasi dari bangsal bedah rumah sakit umum pusat nasional Cipto Mangunkusumo Periode Tahun 2003-2006 (minithesis). Jakarta; Universitas Indonesia; 2009.

4. Salingga I. Obat Generik (Don't Judge it By The Name!). Chem ITB Article. 2011: 2-3.

5. FDA (U.S. Food and Drug Administration). Facts about generic drugs. Med J USA. 2012: $1-4$

6. Happy S. Pola kepekaan kuman Staphylococcus aureus terhadap antibiotika generik dan non generik (minithesis). Padang: Universitas Andalas; 2007.

7. Nagara GK. Uji sensitivitas kuman Pseudomonas aeruginosa terhadap cefoperazon-as. klavulanat sediaan generik dibandingkan dengan bernama dagang (minithesis). Padang: Universitas Andalas; 2007.

8. Andrea D. Penggunaan antibiotik irasional [serial online] 2011 (diunduh tanggal 2 Juli 2013). Tersedia dari: URL: HYPERLINK http://digilibunimus.ac.id. 